\title{
Waterpipe smoking in students: Prevalence, risk factors, symptoms of addiction, and smoke intake. Evidence from one British university Daniel Jackson and Paul Aveyard*
}

\author{
Address: Department of Primary Care \& General Practice, University of Birmingham, Birmingham, B15 2TT, UK \\ Email: Daniel Jackson - DHJ242@adf.bham.ac.uk; Paul Aveyard* - p.n.aveyard@bham.ac.uk \\ * Corresponding author
}

Published: 22 May 2008

BMC Public Health 2008, 8:174 doi:10.1 186/147|-2458-8-174

This article is available from: http://www.biomedcentral.com/I47I-2458/8/174

(c) 2008 Jackson and Aveyard; licensee BioMed Central Ltd.

This is an Open Access article distributed under the terms of the Creative Commons Attribution License (http://creativecommons.org/licenses/by/2.0), which permits unrestricted use, distribution, and reproduction in any medium, provided the original work is properly cited.
Received: 22 November 2007

Accepted: 22 May 2008

\begin{abstract}
Background: Anecdotal reports suggest waterpipe smoking is becoming common in students in western countries. The aim was to examine prevalence, risk factors, symptoms of addiction, and smoke intake.

Methods: This was a cross-sectional survey of students with subsidiary survey of regular waterpipe user and survey of exhaled carbon monoxide ( $\mathrm{CO}$ ) before and after waterpipe smoking in customers of a waterpipe café. 937 students of Birmingham University completed the initial survey with a follow up of 21 regular waterpipe smokers. 63 customers of a waterpipe café near the University completed the study of $\mathrm{CO}$ intake.

Results: 355 (37.9\%, 95\% confidence intervals $(\mathrm{Cl}) 34.8$ to $41.1 \%$ ) students had tried waterpipes, the prevalence of trying rising with duration at University. $75(8.0 \%, 95 \% \mathrm{Cl} 6.4$ to $10.0 \%)$ were regular smokers, similar to the prevalence of cigarette smoking (9.4\%). Although cigarette smoking was the major risk factor for being a regular waterpipe smoker, odds ratio $(95 \% \mathrm{Cl}) 2.77$ (I.52 to $5.06), 65 \%$ of waterpipe smokers did not smoke cigarettes. Seven of 21 (33.3\%) regular waterpipe smokers experienced cravings. Nearly all regular waterpipe users thought it less harmful than smoking cigarettes. The mean (standard deviation) rise in CO was 37.4 (25.8)ppm, nearly twice as high as a typical cigarette smoker seeking cessation treatment.
\end{abstract}

Conclusion: Waterpipe smoking is a common part of student culture in one British university, as in the Middle East and in the United States. It poses a potential threat to public health, with evidence of dependence and high smoke intake.

\section{Background}

Waterpipe smoking is common among young people in Middle Eastern countries, with prevalence estimates of regular smoking of $11 \%-32 \%$ [1-5], and evidence of a recent increase in prevalence [6,7]. Regardless of age, most Syrian smokers began in the 1990s [8].
Data on the prevalence of waterpipe smoking in western societies is limited. A survey of American military at the turn of the century showed only $0.3 \%$ had used waterpipes in the last year [9], while a recent survey of two universities found $15 \%-20 \%$ had smoked a waterpipe in the past month [10]. A convenience sample of regular waterpipe users revealed the majority were young and university educated [11]. 
Studies with a smoking machine reveal that smoke intake from a waterpipe crucially depends upon puff topography $[12,13]$. One study of waterpipe smokers reported the CO boost ranged from 2 to 53 ( $9.5 \%$ carboxyhaemoglobin) parts per million (ppm) in expired air, with a median of $13 \mathrm{ppm}$ ( 2\% carboxyhaemoglobin) [14]. A study of blood carboxyhaemoglobin concentrations in Saudi Arabia showed a mean (standard deviation (SD)) of 10.1\% $(2.5 \%)$, higher than in Saudi cigarette smokers, 6.5\% $(2.7 \%)$ [15]. Nicotine intakes appear to be higher than from cigarette smokers [16], which may explain the emerging evidence of dependence $[17,18]$.

Given the potential for harm from waterpipe smoking, we examined the prevalence, risk factors, intake of smoke, and markers of dependence in one British university.

\section{Method}

Students were asked and volunteered to provide anonymous information in the following two studies with a view to possible publication of the data.

\section{Cross-sectional survey}

In the cross-sectional survey, we randomly selected courses, with probability proportional to size of the course. We distributed a questionnaire in a lecture to the whole year, repeating the process for each of the three years of university. We had resources to study about 1000 students. If the prevalence of waterpipe smoking was about $5 \%$, then we could estimate this with a precision of $+/-1.4 \%$. The survey assessed the ever use and regular use of waterpipes and other tobacco products and basic demographic information.

We asked students to leave a contact for a follow up study. We only contacted students that currently smoked at least monthly. There were 75 of these; of which 24 left contact details and 21 completed the survey. There were no major differences between the 21 regular waterpipe smokers who participated and the 54 who did not. This survey asked students for more details of use of waterpipes, symptoms of addiction, quit attempts, the social acceptability of smoking waterpipes, and perceptions of health effects.

\section{CO monitoring in café users}

We had permission from the proprietor to monitor waterpipe smokers in a café near the University of Birmingham. Most customers were students. We recorded basic demographic data and measured expired CO immediately before and after smoking using a Micro Medical monitor. We timed the smoking session.

\section{Analysis}

We calculated the prevalence of ever and regular use of waterpipes, defined as monthly or more frequent smoking $[17,19,20]$. We examined whether the demographic characteristics were risk factors for having tried waterpipe smoking in a univariate analysis and adjusted for all other factors. We also examined factors that predicted regular use among those who had tried. We calculated proportions, odds ratios (OR), and 95\% confidence intervals $(95 \% \mathrm{CI})$, using logistic regression in SPSS v14.0. For the CO data, we calculated means and SDs for the rise in CO unadjusted and adjusted for other demographic variables using linear regression.

\section{Results}

Cross-sectional survey

937 people completed the cross-sectional survey, and the mean (SD) age was 20.2 (2.5) years. Overall, 149 (15.9\%) were current tobacco users, of which $45(30.2 \%)$ were exclusive waterpipe smokers, 51 (34.2\%) were exclusive cigarette smokers, $3(2.0 \%)$ were exclusive cigar smokers, and $9(6.0 \%)$ exclusive tobacco chewers. The remainder, $41(27.5 \%)$, used more than one form of tobacco, and in 30 this included waterpipes. The prevalence $(95 \% \mathrm{CI})$ of current waterpipe use was $8.0 \%(6.4-10.0 \%)$ (75 students), which was slightly less than the prevalence of cigarette smoking at $9.4 \%(88)$. Of all 75 regular waterpipe smokers, $39(52.0 \%, 4.2 \%(3.0-5.7 \%)$ of all students) smoked weekly or more frequently, with $16(21.3 \%, 1.7 \%$ (1.0-2.8\%) of all students) smoking daily. Cigarette smokers smoked a mean (SD) of 7.7 (11.0) cigarettes/day.

There were 355 (37.9\%, 95\%CI 34.8-41.1\%) students who had tried waterpipes, of whom $75(21.1 \%)$ smoked regularly (at least monthly). The majority, 298 (83.9\%) were introduced by a friend and $21(5.9 \%)$ by family. Males were more likely than females, and those in the second year and third year were more likely to have tried. Four fifths of Arabic students had tried waterpipes, twice as many as in other ethnic groups. Males, those in higher years, Arabic students, and cigarette smokers were more likely to be regular users (Table 1). There was no evidence that gender modified the effect of ethnic group on having ever smoked waterpipes or being a regular user $\left(\chi^{2}=6.65\right.$, $\mathrm{df}=5, \mathrm{p}=0.25$ and $\chi^{2}=7.81, \mathrm{df}=5, \mathrm{p}=0.17$ respectively).

Twenty one of the 75 regular waterpipe smokers completed a more detailed questionnaire. Of these, 17 $(81.0 \%)$ intended to carry on smoking after the ban on smoking in enclosed public spaces was introduced (which was imminent at that time) and 15 (71.4\%) smoked waterpipes at home. All but one smoker felt waterpipe smoking was socially acceptable. Nineteen (90.5\%) thought waterpipe smoking was bad for health, but of these, 13 (68.4\%) thought waterpipes were less damaging 
Table I: Prevalence of having tried and being a regular waterpipe user by demographic characteristics and cigarette use

\begin{tabular}{|c|c|c|c|c|c|c|c|}
\hline & \multirow[b]{2}{*}{ Totals } & \multicolumn{3}{|c|}{ Ever use ( $\mathrm{n}=937$ all students) } & \multicolumn{3}{|c|}{ Regular use ( $\mathrm{n}=355$ all who tried waterpipes) } \\
\hline & & $\mathrm{n}(\%)$ & $\begin{array}{l}\text { Unadjusted OR } \\
(95 \% \mathrm{Cl})\end{array}$ & $\begin{array}{c}\text { Adjusted OR } \\
(95 \% \mathrm{Cl})^{2}\end{array}$ & n (\%) & $\begin{array}{c}\text { Unadjusted OR } \\
(95 \% \mathrm{Cl})\end{array}$ & $\begin{array}{c}\text { Adjusted OR } \\
(95 \% \mathrm{Cl})^{2}\end{array}$ \\
\hline Age & & N/A & $1.02(0.97-1.07)^{\prime}$ & $1.00(0.94-1.06)$ & N/A & $0.91(0.77-1.07)$ & $0.90(0.74-1.10)$ \\
\hline \multicolumn{8}{|l|}{ Gender } \\
\hline Female & $544(58.1)$ & 193 (35.5\%) & 1.00 & 1.00 & $32(16.6 \%)$ & 1.00 & 1.00 \\
\hline Male & $393(41.9)$ & $162(41.2 \%)$ & $1.28(0.98-1.67)$ & $1.49(1.10-2.01)$ & $43(26.5 \%)$ & $1.82(1.09-3.04)$ & $1.86(1.07-3.23)$ \\
\hline \multicolumn{8}{|c|}{ Ethnic group } \\
\hline White & $675(72.0)$ & $257(38.1 \%)$ & 1.00 & 1.00 & $48(18.7 \%)$ & 1.00 & 1.00 \\
\hline Asian & $159(17.0)$ & $65(40.9 \%)$ & $1.13(0.79-1.60)$ & $1.21(0.83-1.75)$ & $16(24.6 \%)$ & $1.42(0.75-2.7 \mathrm{I})$ & $1.65(0.85-3.23)$ \\
\hline Chinese & $36(3.8)$ & $5(13.9 \%)$ & $0.26(0.10-0.68)$ & $0.21(0.08-0.56)$ & $2(40.0 \%)$ & $2.90(0.47-17.85)$ & $2.51(0.38-16.82)$ \\
\hline Black & 46 (4.9) & $12(26.1 \%)$ & $0.57(0.29-1.13)$ & $0.61(0.30-1.24)$ & $3(25.0 \%)$ & $1.45(0.38-5.56)$ & $1.32(0.33-5.36)$ \\
\hline Arab & $16(1.7)$ & 13 (81.3\%) & 7.05 (1.99-24.97) & 6.44 (1.73-23.94) & 5 (38.5\%) & $2.72(0.85-8.69)$ & $2.5 \mathrm{I}(0.74-8.5 \mathrm{I})$ \\
\hline Other & $5(0.5)$ & $3(60.0 \%)$ & $2.44(0.4 I-14.70)$ & $2.38(0.33-17.02)$ & I (33.3\%) & $2.18(0.19-24.50)$ & $1.80(0.12-26.90)$ \\
\hline \multicolumn{8}{|c|}{ Year of course } \\
\hline I & $350(37.4)$ & I0I (28.9\%) & 1.00 & 1.00 & 23 (22.8\%) & 1.00 & 1.00 \\
\hline 2 & $372(39.7)$ & 158 (42.5\%) & $1.82(1.34-2.48)$ & $2.26(1.6 \mathrm{I}-3.18)$ & 31 (19.6\%) & $0.83(0.45-\mid .52)$ & $1.25(0.63-2.47)$ \\
\hline 3 & $215(22.9)$ & $96(44.7 \%)$ & $1.99(1.40-2.84)$ & $2.63(1.74-3.96)$ & 21 (21.9\%) & $0.95(0.49-1.86)$ & $1.79(0.78-4.09)$ \\
\hline \multicolumn{8}{|l|}{ Cig smoking } \\
\hline No & $849(90.6)$ & $286(33.7 \%)$ & 1.00 & 1.00 & 49 (17.1\%) & 1.00 & 1.00 \\
\hline Yes & $88(9.4)$ & 69 (78.4\%) & $7.15(4.22-12.11)$ & $8.06(4.63-14.01)$ & 26 (37.7\%) & $2.93(1.64-5.20)$ & $2.77(1.52-5.06)$ \\
\hline
\end{tabular}

I For a I year increase in age.

2 Adjusted for all variables listed in table

than cigarettes. Of the 21, two (9.5\%) thought smoking waterpipes more damaging than smoking cigarettes. Two $(9.5 \%)$ regular waterpipe smokers had tried to stop smoking waterpipes but restarted. Seven (33.3\%) had experienced cravings to smoke waterpipes.

\section{CO monitoring in café users}

Sixty three people smoking in waterpipe cafés participated in a survey of expired $\mathrm{CO}$ before and after smoking. The mean (SD) age was $22.8(4.3)$ years and $14(21.9 \%)$ were female, and they smoked a mean (SD) of $1.4(1.2)$ times per week. The mean (SD) pre-smoking CO concentration was 5.1 (9.3) ppm. Seven (10.9\%) had levels greater than
9 ppm (indicating current smoking), with two with high readings of 37 and $65 \mathrm{ppm}$ (both regular waterpipe smokers). The sessions lasted between 15 and 60 minutes, with a mean (SD) of 29.6 (10.1) minutes. The mean (SD) reading after waterpipe smoking was 37.4 (25.8) ppm and the mean rise was 31.6 (24.9) ppm

The biggest influence on rise in $\mathrm{CO}$ was duration of smoking. For every 10 minutes smoking, $\mathrm{CO}$ rose by 15.8 (95\%CI $11.0-20.6) \mathrm{ppm}$, explaining $41.6 \%$ of the variance (Table 2). There was some evidence that the rise differed by gender, age, and ethnic group, but these

Table 2: Effects of characteristics of waterpipe smokers and duration of smoking on rise in exhaled carbon monoxide concentration

\begin{tabular}{lccc}
\hline Characteristic & $\mathrm{N}(\%)$ & Unadjusted coefficient $(95 \% \mathrm{Cl})$ for Ppm rise in CO & Adjusted ${ }^{2}$ coefficient $(95 \% \mathrm{Cl})$ for PPm rise in CO \\
\hline Duration of session & $29.6(10.1)^{\prime}$ & $15.8(11.0-20.6)^{3}$ & $14.8(9.3-20.3)^{3}$ \\
Age of participant in years & $22.8(4.3)^{\prime}$ & $1.8(0.4-3.2)^{4}$ & $-0.1(-1.4-1.2)^{4}$ \\
Ethnic group & & & Reference \\
White and others & $43(68.3)$ & Reference & $-5.6(-18.4-7.2)$ \\
Asian & $28(44.4)$ & $-15.5(-29.4-1.7)$ & $-1.9(-15.3-11.5)$ \\
Arab & $15(23.8)$ & $3.7(-12.5-19.9)$ & $6.4(-6.9-19.6)$ \\
Gender & & & Reference \\
Male & $49(77.8)$ & $15.9(5.1-26.6)$ & Reference \\
Female & $14(22.2)$ & &
\end{tabular}

I Mean (SD).

2 Adjusted for all variables in table.

${ }^{3}$ For a 10 minute increase in duration.

${ }^{4}$ For a 1 year increase in age. 
differences were explained by differences in session duration.

\section{Discussion}

This study shows that more than a third of students at one British University have tried waterpipes and of this third, one fifth are regular (at least monthly) users. Regular use of waterpipes was the second most common form of regular tobacco consumption. Most students who smoked waterpipes regularly did not smoke cigarettes. Most regular waterpipe smokers smoked at home. The factors associated with trying waterpipe smoking were similar to those associated with becoming a regular current user. Waterpipe smoking was much more common in males. The likelihood of using waterpipes was similar in all ethnic groups, except those of Arabic ethnic origin, where it was very common. A third of regular smokers showed one symptom of dependence, but this was not assessed further.

The prevalence of trying and regular waterpipe smoking increased with time in the university, which might indicate that waterpipe smoking is propagated through student culture. This is unlike cigarettes, where the prevalence of regular smoking was highest in first year students, though differences between years were small and not statistically significant. The prevalence of current waterpipe use at the only two American universities surveyed was high [10].

The students in this study thought that smoking waterpipes was relatively benign unlike students in Syria [21], but in common with American students [19,22]. It may be this perception of the relative lack of harm that supports the rise of waterpipe smoking in western students. There are no trials of interventions to deter or assist cessation of waterpipe smoking in the Cochrane review [23]. It is possible that presenting data on the known health effects could deter students from using waterpipes.

Our data show high intakes of smoke in typical waterpipe café users in the UK, with exhaled CO levels higher than observed in typical patients seeking help for stopping cigarettes $[24,25]$. Some of this rise might come from inhaling ambient air. Data from elsewhere suggests high intakes of nicotine from waterpipes [26], which could lead to dependence, and high intakes of other tobacco smoke constituents $[27,28]$ causing diseases associated with smoking.

This study has some limitations. It was a cross-sectional study in one university and it is likely that the popularity of new fashions may vary. Some associations we described as risk factors may not be causal. The mean age of café users was higher than the students and the ethnic profile differed with proportionately more Arabic and Asian café users than students.

\section{Conclusion}

These data show that waterpipe smoking is established in UK students, as in the US and we need to monitor the prevalence. It may harm public health and merits further research and a policy response.

\section{Competing interests}

Daniel Jackson, none.

Paul Aveyard. Paul has received hospitality from various pharmaceutical companies, including those making products for smoking cessation. He has received consultancy income to him and his institution from Xenova Biotechnology, Pfizer, and McNeil AB for advice on smoking cessation.

\section{Authors' contributions}

DJ initiated the study and it was planned by both authors. DJ carried out the study and both he and PA analysed the data. DJ wrote the first draft and PA amended it. All authors read and approved the final manuscript.

\section{Acknowledgements}

We are grateful to the students, the café owner, and his customers that participated. Lesley Roberts and Suzan Ahmed helped guide the study. The study was funded by the University of Birmingham and Paul Aveyard is funded by a NIHR Career Scientist Award. Neither the University of Birmingham nor the NIHR had a role in study design, collection, analysis, interpretation of results or in the decision to publish.

\section{References}

I. Varsano S, Ganz I, Eldor N, Garenkin M: Water-pipe tobacco smoking among school children in Israel: frequencies, habits, and attitudes. Harefuah 2003, I 42(I I):736-74I, 807.

2. Refaat A: Practice and awareness of health risk behaviour among Egyptian university students. Eastern Mediterranean Health Journal 2004, 10:72-8I [http://www.emro.who.int/Publications/ EMH]/I00I 2/Practice.htm].

3. Zoughaib SS, Adib SM, Jabbour J: Prevalence and determinants of water pipe or narghile use among students in Beirut's southern suburbs. J Med Liban 2004, 52(3): | 42- I 48.

4. Tamim H, Terro A, Kassem H, Ghazi A, Khamis TA, Hay MM, Musharrafieh U: Tobacco use by university students, Lebanon, 200 I. Addiction 2003, 98:933-939.

5. Maziak W, Fouad FM, Asfar T, Hammal F, Bachir EM, Rastam S, Eissenberg T, Ward KD: Prevalence and characteristics of narghile smoking among university students in Syria. Int J Tuberc Lung Dis 2004, 8:882-889.

6. Momenan AA, Etemadi A, Ghanbarian A, Azizi F: The Rising Prevalence of Waterpipe Smoking among Iranian Adolescents: Tehran Lipid and Glucose Study. 2006.

7. Chaaya M, El Roueiheb Z, Chemaitelly H: Argileh smoking among university students: a new tobacco epidemic. Nicotine and Tobacco Research 2004, 6:457-463.

8. Rastam S, Ward K, Eissenberg T, Maziak W: Estimating the beginning of the waterpipe epidemic in Syria. BMC Public Health 2004, 4:32.

9. Ward KD, Vander Weg MW, Relyea G, DeBon M, Klesges RC: Waterpipe smoking among American military recruits. Prev Med 2006, 43:92-97.

10. Smith-Simone S, Maziak W, Ward KD, Eissenberg T: Waterpipe smoking on two US college campuses. 2007. 
11. Ward KD, Eissenberg TE, Gray J, Srinivas V, Wilson N, Maziak W: Characteristics of American waterpipe users: a preliminary report. Nicotine and Tobacco Research 2007 in press.

12. Shihadeh A, Saleh R: Polycyclic aromatic hydrocarbons, carbon monoxide, "tar", and nicotine in the mainstream smoke aerosol of the narghile water pipe. Food Chem Toxicol 2005, 43:655-66I.

13. Shihadeh A: Investigation of mainstream smoke aerosol of the argileh water pipe. Food Chem Toxicol 2003, 4I: 143-I52.

14. Shihadeh A, Rastam S, Katurji W, Maziak W, Eissenberg T, Ward K: Effect of smoke $\mathrm{CO}$ concentration and overall puff duration on $\mathrm{CO}$ boost in waterpipe smokers: direct evidence linking toxicant exposure and uptake. Washington DC; 2006.

15. Zahran FM, Ardawi MS, Al-Fayez SF: Carboxyhemoglobin concentrations in smokers of sheesha and cigarettes in Saudi Arabia. Br Med J 1985, 29 I:1768-1770.

16. Maziak W, Ward KD, Afifi Soweid RA, Eissenberg T: Tobacco smoking using a waterpipe: a re-emerging strain in a global epidemic. Tob Control 2004, 13:327-333.

17. Maziak W, Eissenberg T, Ward KD: Patterns of waterpipe use and dependence: implications for intervention development. Pharmacol Biochem Behav 2005, 80: I73-179.

18. Maziak W, Eissenberg TE, Ward KD: Factors related to level of narghile use: the first insights on tobacco dependence in narghile users. Drug Alcohol Depend 2004, 76: I0I-106.

19. Smith SY, Curbow B, Stillman FA: Harm perception of nicotine products in college freshmen. In Nicotine \&amp; Tobacco Research Volume 9. Informa Healthcare; 2007:977-982.

20. Maziak W, Ward KD, fifi Soweid RA, Eissenberg T: Standardizing questionnaire items for the assessment of waterpipe tobacco use in epidemiological studies. Public Health 2005, I 1 9:400-404.

21. Maziak W, Eissenberg T, Rastam S, Hammal F, Asfar T, Bachir ME, Fouad MF, Ward KD: Beliefs and attitudes related to narghile (waterpipe) smoking among university students in Syria. Ann Epidemiol 2004, 14:646-654.

22. Smith-Simone S, Maziak W, Ward KD, Eissenberg T: Waterpipe Tobacco Smoking: Knowledge, Attitudes, Beliefs, and Behavior in Two U.S. Samples. Nicotine and Tobacco Research 2007 in press.

23. Maziak W, Ward KD, Eissenberg T: Interventions for waterpipe smoking cessation. Cochrane Database of Systematic Reviews: Reviews 2007 Issue 4 John Wiley \& Sons, Ltd Chichester, UK DOI: 10 1002/I465I858 CD005549 pub2 2007.

24. Stapleton JA, Russell MA, Feyerabend C, Wiseman SM, Gustavsson G, Sawe $U$, Wiseman $D$, ., .. Dose effects and predictors of outcome in a randomized trial of transdermal nicotine patches in general practice. Addiction 1995, 90:31-42.

25. Aveyard P, Brown K, Saunders C, Alexander A, Johnstone E, Munafo $M$, Murphy $M$ : A randomised controlled trial of weekly versus basic smoking cessation support in primary care. Thorax 2007 62:898-903.

26. Neergaard J, Singh P, Job J, Montgomery S: Waterpipe smoking and nicotine exposure: A review of the current evidence. In Nicotine \&amp; Tobacco Research Volume 9. Informa Healthcare; 2007:987-994.

27. Shihadeh A, Saleh R: Polycyclic aromatic hydrocarbons, carbon monoxide, "tar", and nicotine in the mainstream smoke aerosol of the narghile water pipe. Food Chem Toxicol 2005, 43:655-661.

28. Shihadeh A: Investigation of mainstream smoke aerosol of the argileh water pipe. Food Chem Toxicol 2003, 4I: I43-I52.

\section{Pre-publication history}

The pre-publication history for this paper can be accessed here:

http://www.biomedcentral.com/1471-2458/8/174/pre pub
Publish with Biomed Central and every scientist can read your work free of charge

"BioMed Central will be the most significant development for disseminating the results of biomedical research in our lifetime. "

Sir Paul Nurse, Cancer Research UK

Your research papers will be:

- available free of charge to the entire biomedical community

- peer reviewed and published immediately upon acceptance

- cited in PubMed and archived on PubMed Central

- yours - you keep the copyright
Biomedcentral 